\title{
IMWII Incarceration History and Uncontrolled Blood Pressure in a Multi-Site Cohort \\ .
}

\author{
Benjamin A. Howell, MD MPH ${ }^{7}$, Jessica B. Long, $M P H^{7}$, E. Jennifer Edelman, $M D M H S^{1,2}$, \\ Kathleen A. McGinnis, DrPH MS ${ }^{3}$, David Rimland, $\mathrm{MD}^{4,5}$, David A. Fiellin, $\mathrm{MD}^{1,2}$, \\ Amy C. Justice, $M D P h D^{1,2,3}$, and Emily A. Wang, MD MAS
}

'Department of Internal Medicine, Yale University School of Medicine, New Haven, CT, USA; ${ }^{2}$ Center for Interdisciplinary Research on AIDS, Yale University School of Public Health, New Haven, CT, USA; ${ }^{3}$ Veterans Administration Connecticut Healthcare System, West Haven, CT, USA; ${ }^{4}$ Atlanta VA Medical Center, Atlanta, GA, USA; ${ }^{5}$ Emory University School of Medicine, Atlanta, GA, USA.

BACKGROUND: Incarceration is associated with increased risk of hypertension and cardiovascular disease mortality. We used data from the Veterans Aging Cohort Study (VACS) to explore the impact of incarceration on blood pressure (BP) control.

METHODS: Among hypertensive VACS participants, we measured the association between self-reported recent incarceration or past (not recent) history of incarceration and BP control in the year following the survey. To analyze the association between incarceration and BP control, we used logistic regression models adjusted for sociodemographic characteristics, clinical factors (HIV status and body mass index), and behavioral factors (history of smoking, unhealthy alcohol use, illicit drug use). We explored potential mediators including post-traumatic stress disorder (PTSD), depression, primary care engagement, and adherence to antihypertensive medications.

RESULTS: Among the 3515 eligible VACS participants, 2304 participants met the inclusion criteria. Of these, 163 (7\%) reported recent incarceration, and 904 (39\%) reported a past history of incarceration. Participants with recent or past history of incarceration were more likely to have uncontrolled BP than those without a history of incarceration (67 \% vs. $56 \%$ vs. $51 \%, p<0.001$ ). In multivariable analysis, recent incarceration (adjusted odds ratio $[\mathrm{AOR}]=1.5795 \%$ confidence interval $[\mathrm{CI}]$ : 1.09-2.26), but not a past history of incarceration (AOR= $1.0895 \%$ CI: 0.90-1.30), was associated with uncontrolled BP compared with those who were never incarcerated.

CONCLUSIONS: Among patients with a history of hypertension, recent incarceration is associated with having uncontrolled BP following release. Interventions are needed for recently released individuals to improve hypertension outcomes.

KEY WORDS: hypertension/epidemiology; hypertension/therapy; prisoners; socioeconomic factors; chronic disease/epidemiology; chronic disease/therapy; incarceration.

Electronic supplementary material The online version of this article (doi:10.1007/s11606-016-3857-1) contains supplementary material, which is available to authorized users.

Received December 11, 2015

Revised June 2, 2016

Accepted August 18, 2016

Published online September 12, 2016
$\mathrm{J}$ Gen Intern Med 31(12): 1496-502

DOI: $10.1007 / \mathrm{s} 11606-016-3857-1$

(c) Society of General Internal Medicine 2016

\section{INTRODUCTION}

Incarceration rates in the United States have risen exponentially, with $500 \%$ growth since $1970 .{ }^{1}$ The US incarcerated population today stands at more than 2.2 million. $^{2}$ At the current rate, 1 in 15 people, and 1 in 3 black men, will be incarcerated in federal or state prisons in their lifetimes. ${ }^{3}$ People with a history of incarceration have higher rates of chronic medical conditions ${ }^{4-7}$ and risk of death than the general population. ${ }^{8-10}$ Importantly, cardiovascular disease is a leading cause of death among individuals with prior incarceration. $^{8,11,12}$

The association between a history of incarceration and increased risk of cardiovascular disease may be partially explained by an increased prevalence of cardiovascular risk factors in this population, especially hypertension, although the mechanisms are not known. ${ }^{6,7,13}$ Effective control of hypertension is a well-studied method of averting serious cardiovascular outcomes, including ischemic heart disease, cerebrovascular disease, heart failure, chronic kidney disease, and peripheral vascular disease. ${ }^{14}$ It is not known how recent release from a correctional facility and a history of incarceration affect blood pressure (BP) control.

We used data from the Veterans Aging Cohort Study (VACS) to measure the association between incarceration and BP control following release in patients with hypertension and to evaluate putative mechanisms of observed associations. We hypothesized that in a population of patients with hypertension and a history of incarceration, recent or past, would be associated with uncontrolled BP.

\section{METHODS}

\section{Sample}

As previously described, VACS is a longitudinal, prospective, multi-site observational study of HIV-infected veterans and 
matched uninfected veterans who receive healthcare services in the Veterans Health Administration (VHA). ${ }^{15}$ Briefly, VACS assesses a combination of self-reported, administrative, and clinical data from eight VHA clinical sites. Data collected include measures of patients' sociodemographic characteristics, comorbidities, and health behaviors. The institutional review boards at all locations approved the study, and all participants provided written informed consent prior to enrollment. We included VACS participants who completed the study followup survey between October 1, 2009, and September 30, 2010, who answered questions regarding incarceration history, and who met criteria for hypertension prior to the survey.

Participants met the criteria for hypertension if 1) on two instances during the period from 12 to 24 months prior to the survey, separated by at least 7 days, they had a systolic BP $\geq 140 \mathrm{mmHg}$ or a diastolic $\mathrm{BP} \geq 90 \mathrm{mmHg}$ measured at any clinical encounter, or 2) they filled a prescription for an antihypertensive medication using VHA pharmacy refill data. ${ }^{16}$ As part of routine clinical visits, trained clinical staff measured BP using standard VHA protocols.

\section{Exposure: History of Incarceration}

We used two questions to assess history of incarceration. One question was "Have you ever spent any time in a jail, prison, detention center, or juvenile correctional facility?" to which participants could answer "yes," "no," or "don't know." A second question was "In the past year, how much time have you spent in a jail, prison, or detention center?" Using answers to these two questions, we categorized participants as having a recent history of incarceration (within the last year), a past history of incarceration (during lifetime but not during the last year), or no history of incarceration. Participants who did not answer these incarceration questions or answered "don't know" were not included in our analysis.

We described additional characteristics of incarceration history including number of times incarcerated and total time spent incarcerated. We also assessed participation in Veterans Justice Outreach (VJO) and Healthcare Re-entry for Veterans (HCRV), using clinic stop codes on outpatient encounters. ${ }^{12}$ The HCRV program provides pre-release outreach and postrelease case management services for incarcerated veterans released from state and federal prisons. The VJO initiative targets homelessness among veterans in contact with law enforcement, jails, and the courts by connecting them with treatment and social service resources.

\section{Outcome: BP Control}

We measured BP control using clinical data collected over the 12 months following the date the survey was administered. Uncontrolled BP was defined as a measured systolic BP $\geq 140 \mathrm{mmHg}$ or a diastolic $\mathrm{BP} \geq 90 \mathrm{mmHg}$ on two separate occasions at least 7 days apart in the 12 months following the survey. We also performed sensitivity analyses using a poorly controlled $\mathrm{BP}$, defined as systolic $\mathrm{BP} \geq 160 \mathrm{mmHg}$ or diastolic
$\mathrm{BP} \geq 100 \mathrm{mmHg}$, as the outcome and the percentage of months that a person had BP controlled. ${ }^{17}$ Additionally, we measured the mean systolic BP and diastolic BP values during the 12 months following the survey.

\section{Construction of Variables}

We assessed age (continuous), HIV status (infected vs. uninfected), sex (male vs. female), race/ethnicity (black vs. nonblack), education (<high school graduation vs. high school graduation and beyond), income $(<\$ 12,000 /$ year vs. $\geq \$ 12,000 /$ year), body mass index (BMI, $\geq 25$ vs. $<25$ ), unstable housing, unhealthy alcohol use, smoking (current vs. prior/ never), and illicit drug use. We defined unstable housing as having spent at least one night in the year prior to survey in a homeless shelter, on the street, in a welfare hotel, in emergency/temporary housing or halfway house, doubled up with others, or in drug treatment. We classified persons as having unhealthy alcohol use if their total score on the Alcohol Use Disorders Identification Test-Consumption (AUDIT-C) was $\geq 4$ and they reported drinking alcohol in the past year. ${ }^{18 \text {, }}$

${ }^{19}$ We defined recent drug use as self-reported weekly use of cocaine, stimulants, or heroin, non-medical use of prescription opioids, or any intravenous drug use in the past year.

We evaluated post-traumatic stress disorder (PTSD), depression, primary care engagement, and antihypertensive medication adherence. We identified PTSD according to the diagnosis codes on at least one inpatient or two outpatient encounters. ${ }^{20}$ We used a score of $\geq 10$ on the Patient Health Questionnaire-9 to indicate active depressive symptoms. ${ }^{21}$

We measured primary care engagement using data from the VHA administrative database and defined it as $\geq 2$ primary care visits at least 90 days apart in the period 12 to 24 months before the survey and, separately, the immediate 12 months following the survey. ${ }^{22}$ We measured receipt of antihypertensive medications in the 12 months following the survey using classification codes from the VHA pharmacy refill data, and then calculated the medication possession ratio as the percentage of days with antihypertensive medication. ${ }^{23}$

\section{Statistical Analysis}

We described baseline characteristics by category of incarceration history (recent incarceration in the last year, past incarceration, or no history of incarceration). We also described the systolic and diastolic BP, control of BP, and receipt of antihypertensive medication. We used chi-square tests for categorical variables and ANOVA for continuous variables to compare between categories.

Next we performed logistic regression, examining the association between incarceration history and uncontrolled BP. We adjusted for covariates that we hypothesized a priori would confound the relationship between incarceration and BP control in a series of sequential multivariable models. Model 1 controlled for age, HIV status, sex, race/ethnicity, educational attainment, income, BMI, and housing status. For Model 2, we 
Table 1 Baseline Characteristics of the Study Sample by Incarceration History $(N=\mathbf{2 3 0 4})$

\begin{tabular}{|c|c|c|c|c|c|c|c|}
\hline & \multicolumn{2}{|c|}{$\begin{array}{l}\text { Recent } \\
\text { incarceration }\end{array}$} & \multicolumn{2}{|c|}{$\begin{array}{l}\text { Past history of } \\
\text { incarceration }\end{array}$} & \multicolumn{2}{|c|}{$\begin{array}{l}\text { Never } \\
\text { incarcerated }\end{array}$} & \multirow[t]{2}{*}{$\begin{array}{l}\text { Chi-square } \\
p \text {-value }\end{array}$} \\
\hline & No. & $\%$ & No. & $\%$ & No. & $\%$ & \\
\hline Total & 163 & 7 & 904 & 39 & 1237 & 54 & \\
\hline Age, years (mean, SD*) & 55.7 & 6.2 & 57.1 & 7.3 & 58.9 & 9.2 & $<0.001$ \\
\hline HIV infected at baseline & 72 & 44 & 412 & 46 & 593 & 48 & 0.44 \\
\hline Male & 157 & 96 & 888 & 98 & 1145 & 93 & $<0.001$ \\
\hline Black race & 133 & 82 & 680 & 75 & 756 & 61 & $<0.001$ \\
\hline \multicolumn{8}{|l|}{ Education } \\
\hline$<$ High school & 16 & 10 & 61 & 7 & 72 & 6 & \multirow[t]{3}{*}{0.040} \\
\hline$\geq$ High school & 141 & 87 & 827 & 91 & 1150 & 93 & \\
\hline Missing & 6 & 4 & 16 & 2 & 15 & 1 & \\
\hline \multicolumn{8}{|l|}{ Low income } \\
\hline No & 107 & 66 & 474 & 52 & 465 & 38 & \multirow[t]{3}{*}{$<0.001$} \\
\hline Yes & 52 & 32 & 396 & 44 & 731 & 59 & \\
\hline Missing & 4 & 2 & 34 & 4 & 41 & 3 & \\
\hline \multicolumn{8}{|l|}{$\mathrm{BMI}^{\dagger}$} \\
\hline$<25$ & 29 & 18 & 228 & 25 & 280 & 23 & \multirow[t]{3}{*}{0.045} \\
\hline$\geq 25$ & 99 & 61 & 491 & 54 & 740 & 60 & \\
\hline $\bar{M}$ issing & 35 & 21 & 185 & 20 & 217 & 18 & \\
\hline Unstable housing & 78 & 48 & 196 & 22 & 138 & 11 & $<0.001$ \\
\hline Current smoker & 94 & 58 & 430 & 48 & 322 & 26 & $<0.001$ \\
\hline \multicolumn{8}{|l|}{ Unhealthy alcohol use } \\
\hline Yes & 48 & 29 & 180 & 20 & 163 & 13 & \multirow[t]{3}{*}{$<0.001$} \\
\hline Low-risk/non-drinker & 111 & 68 & 687 & 76 & 986 & 80 & \\
\hline Missing & 4 & 2 & 37 & 4 & 88 & 7 & \\
\hline Illicit drug use in past year & 36 & 22 & 165 & 18 & 124 & 10 & $<0.001$ \\
\hline Engaged in primary care (pre-survey) & 149 & 91 & 864 & 96 & 1165 & 94 & 0.070 \\
\hline $\mathrm{HCRV}^{\S}$ or $\mathrm{VJO}^{\| l}$ participation & 17 & 10 & 18 & 2 & NA & & $<0.001$ \\
\hline PTSD $^{\text {II }}$ & 36 & 22 & 155 & 17 & 181 & 15 & 0.030 \\
\hline Depression & 68 & 0.42 & 222 & 0.25 & 233 & 0.19 & $<0.001$ \\
\hline Engaged in primary care (after survey) & 144 & 88 & 802 & 89 & 1061 & 86 & 0.12 \\
\hline Antihypertensive adherent & 69 & 42 & 463 & 51 & 655 & 53 & 0.040 \\
\hline
\end{tabular}

*Standard deviation, $p$-value from ANOVA analysis

Body mass index

Illicit drug use $=$ weekly cocaine, stimulant, heroin, non-prescription opioid use, or any intravenous drug use in past year

${ }^{\S}$ Health Care for Re-entry Veterans

"Veterans Justice Outreach

"Post-traumatic stress disorder

added behavioral factors: history of unhealthy alcohol use, smoking, illicit drug use, and primary care engagement prior to the survey.

We then performed mediation analyses to determine the influence of PTSD, depression, primary care engagement after the survey, and antihypertensive adherence on the relationship between incarceration history and BP control using Baron and Kenny mediation analysis. ${ }^{24}$ This was a three-step process to determine whether (1) incarceration was associated with BP control, (2) incarceration was associated with the potential mediators, and (3) the association between incarceration and BP control was attenuated after adjustment for the potential mediators.

A $p$-value of $<0.05$ for was considered statistically significant. All statistical analyses were performed using SAS version 9.4 software (SAS Institute Inc., Cary, NC). We used variance inflation factor in the model with the most covariates to assess multicollinearity of covariates.

\section{RESULTS}

Among the 3515 VACS participants who completed the survey, 2304 participants met our inclusion criteria of having hypertension and non-missing incarceration data. We excluded 136 participants who did not respond to questions on incarceration history, 258 participants who lacked BP measurements, and 817 who did not meet our criteria for hypertension. Of the 2304 in our study sample, 163 (7\%) reported recent incarceration and 904 (39\%) reported a past history of incarceration. Participants with recent or past history of incarceration were more likely to be younger and male, to have a low annual income, to not have completed high school, to have unhealthy alcohol use, and to report current smoking and illicit drug use compared with those who did not report a history of incarceration (Table 1).

Individuals recently incarcerated reported having more incarceration episodes with longer cumulative time incarcerated than those who reported a past history of incarceration. Participation in either VHA intervention program (HCRV or VJO) for veterans with criminal justice involvement was low among those with either recent $(10 \%)$ or past (2\%) incarceration.

Participants with recent incarceration or past history of incarceration were more likely to have uncontrolled BP than those without a history of incarceration $(67 \%$ vs. $56 \%$ vs. $51 \%, p<0.001$; Table 2). We did not observe a statistical difference in mean systolic BP according to incarceration 
Table 2 Blood Pressure Control and Treatment by Incarceration History

\begin{tabular}{|c|c|c|c|c|c|c|c|}
\hline \multirow[b]{2}{*}{ Blood pressure control } & \multicolumn{2}{|c|}{$\begin{array}{l}\text { Recent } \\
\text { incarceration }\end{array}$} & \multicolumn{2}{|c|}{$\begin{array}{l}\text { Past history of } \\
\text { incarceration }\end{array}$} & \multicolumn{2}{|c|}{ Never incarcerated } & \multirow[t]{2}{*}{$p$-value $*$} \\
\hline & $\mathrm{N}$ & $\%$ & $\mathrm{~N}$ & $\%$ & $\mathrm{~N}$ & $\%$ & \\
\hline Uncontrolled $(\geq 140 / \geq 90 \mathrm{mmHg})$ & 110 & 67 & 510 & 56 & 628 & 51 & $<0.001$ \\
\hline Poorly controlled $(\geq 160 / \geq 100 \mathrm{mmHg})$ & 50 & 31 & 182 & 20 & 223 & 18 & 0.001 \\
\hline Blood pressure, $\mathrm{mmHg}$ & Mean & SD & Mean & $\mathrm{SD}$ & Mean & $\mathrm{SD}$ & \\
\hline Systolic & 132.1 & 12.1 & 131.1 & 12.2 & 130.4 & 12.6 & 0.19 \\
\hline Diastolic & 80.5 & 8.4 & 79.7 & 8.6 & 78.0 & 9.2 & $<0.001$ \\
\hline
\end{tabular}

*Chi-square test for control and ANOVA for continuous blood pressure

history. We did note higher mean diastolic $\mathrm{BP}(80.5 \mathrm{mmHg})$ in those with recent incarceration compared to those with past history of incarceration $(79.7 \mathrm{mmHg})$ or who were never incarcerated $(78.0 \mathrm{mmHg}, p<0.001)$. We observed a difference in the distribution of BP values between the categories of incarceration history (Online Appendix Fig. 1). The upper quartile limits for systolic BP and diastolic BP were $141 \mathrm{mmHg}$ and $87 \mathrm{mmHg}, 139 \mathrm{mmHg}$ and $85 \mathrm{mmHg}$, and $138 \mathrm{mmHg}$ and $84 \mathrm{mmHg}$ in those with recent incarceration, with past history of incarceration, and never incarcerated, respectively.

In the unadjusted analysis, recent incarceration $(\mathrm{OR}=2.01$, $95 \%$ CI: 1.42-2.85) and past history of incarceration (OR = 1.26, $95 \%$ CI: 1.06-1.49) were associated with uncontrolled BP in the year after the survey compared with participants without a history of incarceration (Table 3). In Model 1, the association between recent incarceration and uncontrolled BP persisted after controlling for age, HIV status, sex, race/ethnicity, educational attainment, income, BMI and housing status (adjusted odds ratio $[\mathrm{AOR}]=1.64,95 \% \mathrm{CI}$ : 1.14 2.36) when compared to those who were never incarcerated. However, the association between past history of incarceration and uncontrolled BP did not persist in this adjusted model $(\mathrm{AOR}=1.12,95 \% \mathrm{CI}: 0.94-1.34)$. The association between recent incarceration and uncontrolled BP compared with those who were never incarcerated also persisted in Model 2, which also controlled for history of smoking, unhealthy alcohol use, illicit drug use, and primary care engagement prior to the survey (AOR 1.57, $95 \%$ CI: 1.09-2.26).

We explored PTSD, depression, primary care engagement after the survey, and antihypertensive adherence as putative mediators. Primary care engagement after the survey did not meet the requirement of being associated with both the exposure (incarceration history) and outcome (uncontrolled hypertension). In the mediation analysis, we ran separate models adding PTSD, depression, or antihypertensive adherence separately to those variables in Model 2. The adjusted odds ratio of recent incarceration compared to never incarceration was not significantly impacted when we added PTSD (recent vs. never incarcerated AOR 1.55, $95 \%$ CI: 1.07-2.23) or depression (recent vs. never incarcerated AOR 1.49, 95 \% CI: 1.03 2.16) or antihypertensive adherence (recent vs. never incarcerated AOR 1.58, $95 \%$ CI: 1.09-2.27).
In the sensitivity analysis using a higher cutoff for $\mathrm{BP}$ control (SBP $\geq 160$ or $\mathrm{DBP} \geq 100$ ), we found that participants with recent incarceration or past history of incarceration were more likely to have poorly controlled BP than those without a history of incarceration ( $31 \%$ vs. $20 \%$ vs. $18 \%, p=0.001$; Table 2). The association between recent incarceration and poorly controlled BP in the fully adjusted model was consistent in effect magnitude and direction (Online Appendix Table 1). We also found that participants with recent incarceration had a lower percentage of months of controlled BP than those without a history of incarceration ( $72 \%$ vs. $76 \%$ vs. $78 \%$, recent vs. never $p=0.005$, past vs. never $p=0.09$ ).

\section{DISCUSSION}

In a large multi-site cohort study, we found that among participants with hypertension, a recent history of incarceration was associated with increased odds of having uncontrolled BP. Previous studies have suggested that known mechanisms such as HIV status, educational status, low income, BMI, housing status, unhealthy alcohol use, and illicit drug use, all of which are more frequent in people with a history of incarceration, can explain disparities in hypertension outcomes in patients with a history of incarceration, but our study suggests that other mechanisms may play a role..$^{8,13}$

Recent incarceration could have an adverse effect on BP control, particularly impacting control of diastolic BP. The period immediately after release from prison or jail can lead to discontinuity in medical care and instability in many facets of life; people have many competing concerns, including finding housing and employment and reunifying with family, in addition to managing chronic medical issues and engaging in healthcare. ${ }^{25}$, ${ }^{26}$ While we did not find that housing status or income level impacted the association between recent incarceration and hypertension, increased levels of stress during incarceration or in the post-incarceration period may complicate BP control following release from a correctional facility. ${ }^{27-29}$ We also found that individuals with recent incarceration were incarcerated more times and for a longer cumulative time than those who had a past history of incarceration. Therefore, recent incarceration may be a marker for a different pattern of exposure to the criminal justice system, which has an effect on BP control. 
Table 3 Association Between Incarceration History and Uncontrolled Blood Pressure

\begin{tabular}{|c|c|c|c|}
\hline & Bivariate Models & Multivariable Model 1 & Multivariable Model 2 \\
\hline & OR (95 \% CI) & OR (95\% CI) & OR (95\% CI) \\
\hline \multicolumn{4}{|l|}{ Incarceration history } \\
\hline Never incarcerated & Reference & Reference & Reference \\
\hline Past history of incarceration & $1.26(1.06-1.49)$ & $1.12(0.94-1.34)$ & $1.08(0.90-1.30)$ \\
\hline Recent incarceration & $2.01(1.42-2.85)$ & $1.64(1.14-2.36)$ & $1.57(1.09-2.26)$ \\
\hline Age, years & $1.00(0.99-1.01)$ & $1.01(1.00-1.02)$ & $1.01(1.00-1.02)$ \\
\hline \multicolumn{4}{|l|}{ HIV status at baseline } \\
\hline Non-infected & Reference & Reference & Reference \\
\hline Infected & $0.87(0.74-1.03)$ & $0.86(0.72-1.02)$ & $0.86(0.72-1.03)$ \\
\hline \multicolumn{4}{|l|}{ Sex } \\
\hline Female & Reference & Reference & Reference \\
\hline Male & $1.28(0.88-1.87)$ & $1.28(0.86-1.89)$ & $1.30(0.88-1.93)$ \\
\hline \multicolumn{4}{|l|}{ Race } \\
\hline Non-black & Reference & Reference & Reference \\
\hline Black & $1.72(1.44-2.05)$ & $1.63(1.36-1.96)$ & $1.64(1.37-1.98)$ \\
\hline \multicolumn{4}{|l|}{ Education } \\
\hline$<$ High school & Reference & Reference & Reference \\
\hline$>$ High school & $0.85(0.61-1.19)$ & $0.97(0.69-1.38)$ & $0.96(0.68-1.36)$ \\
\hline Missing & $1.20(0.57-2.52)$ & $1.20(0.56-2.60)$ & $1.23(0.57-2.65)$ \\
\hline \multicolumn{4}{|l|}{ Low income } \\
\hline No & Reference & Reference & Reference \\
\hline Yes & $1.41(1.20-1.67)$ & $1.29(1.09-1.54)$ & $1.28(1.07-1.53)$ \\
\hline Missing & $1.19(0.75-1.88)$ & $1.08(0.67-1.73)$ & $1.08(0.67-1.74)$ \\
\hline \multicolumn{4}{|l|}{ BMI* } \\
\hline$<25$ & Reference & Reference & Reference \\
\hline$\geq 25$ & $1.10(0.90-1.34)$ & $1.11(0.90-1.38)$ & $1.14(0.92-1.41)$ \\
\hline Unknown & $1.07(0.83-1.38)$ & $1.05(0.81-1.37)$ & $1.06(0.81-1.37)$ \\
\hline \multicolumn{4}{|l|}{ Unstable housing } \\
\hline No/Unknown & Reference & Reference & Reference \\
\hline Yes & $1.38(1.11-1.72)$ & $1.15(0.92-1.45)$ & $1.10(0.87-1.39)$ \\
\hline \multicolumn{4}{|l|}{ History of smoking } \\
\hline Other & Reference & & Reference \\
\hline Current & $1.24(1.05-1.47)$ & & $1.08(0.90-1.30)$ \\
\hline \multicolumn{4}{|l|}{ Unhealthy alcohol use } \\
\hline Low-risk/non-drinker & Reference & & Reference \\
\hline Yes & $1.10(0.88-1.37)$ & & $1.02(0.81-1.28)$ \\
\hline Missing & $1.02(0.71-1.46)$ & & $1.06(0.73-1.52)$ \\
\hline \multicolumn{4}{|l|}{ Illicit drug use in past year } \\
\hline No & Reference & & Reference \\
\hline Yes & $1.49(1.17-1.89)$ & & $1.43(1.11-1.83)$ \\
\hline \multicolumn{4}{|c|}{ Primary care engagement (pre-survey) } \\
\hline No & Reference & & Reference \\
\hline Yes & $0.88(0.61-1.27)$ & & $0.90(0.62-1.31)$ \\
\hline \multicolumn{4}{|l|}{$\mathrm{PTSD}^{\dagger}$} \\
\hline No & Reference & & \\
\hline Yes & $1.27(1.02-1.59)$ & & \\
\hline \multicolumn{4}{|l|}{ Depression } \\
\hline No/Missing & Reference & & \\
\hline Yes & $1.46(1.20-1.79)$ & & \\
\hline \multicolumn{4}{|c|}{ Primary care engagement (after survey) } \\
\hline No & Reference & & \\
\hline Yes & $2.87(2.22-3.72)$ & & \\
\hline \multicolumn{4}{|l|}{ Antihypertensive adherent } \\
\hline No & Reference & & \\
\hline Yes & $1.22(1.03-1.43)$ & & \\
\hline
\end{tabular}

*Body mass index

Post-traumatic stress disorder

Furthermore, although healthcare is constitutionally mandated while people are incarcerated and patients have access to antihypertensive medications, most incarcerated patients are not permitted to manage their own medications while incarcerated and have low rates of health literacy. Thus, patients can be released back to the community without skills in selfmanagement and are unable to adhere to their medications on release. ${ }^{30}$ Adherence could play a larger role in BP control outside the VHA, where individuals may not have access to healthcare. Another possible factor is that provider behaviors differ when engaging with patients with a history of incarceration, either because of the stigma associated with incarceration or concerns around discontinuity of care.

Other explanations for worse control of hypertension that warrant exploration include care coordination, which could improve management of chronic conditions. ${ }^{31-33}$ In our study, we found that few individuals just released from correctional facilities were connected with the VHA reentry programs. ${ }^{34}$ Implementation of these reentry programs is varied, suggesting a possible intervention model that includes more 
widespread engagement prior to release, to improve BP control in patients with recent incarceration. ${ }^{12,35,36}$ Further study of these programs is needed, as increased participation may ameliorate some of the adverse cardiovascular health effects associated with release from prison or jail.

Given our findings, providers may consider screening for a recent history of incarceration, as it may alert them to patients who need extra attention to improve BP control. Moreover, as several other studies have shown that recent incarceration is associated with worse control of other chronic conditions, the benefits of screening are not limited to BP control. ${ }^{37-39}$ That said, if the health effect of having a history of incarceration is mediated by stigma and provider behaviors, screening for incarceration history may have a detrimental effect. ${ }^{30}$

There are several limitations to our study. Given that this is an observational study, we cannot attribute causality to the associations we observed. History of incarceration, unhealthy alcohol use, smoking, and illicit drug use were self-reported, so social desirability bias may be present. In addition, although we controlled for the effect of unhealthy alcohol use and illicit drug use on BP control, we were not able to control for severe substance use disorders, which may have a greater effect on BP control. We measured BP control differently from another national study in the VHA population, but in sensitivity analysis using their measure found similar levels of BP control. ${ }^{17}$ Also, although we found a significant association between worse BP control and recent incarceration, the difference in mean systolic BP was not significant, and the difference in diastolic BP was relatively small. Studies have shown that in younger patients, elevated diastolic BP is a better predictor of future coronary heart disease than systolic $\mathrm{BP}^{40}$ The analysis of continuous measurements of systolic and diastolic BP does not convey the clinical importance of certain threshold values.

There is also danger of misclassification of receipt of antihypertensive medications, as these medications can be prescribed for other indications, such as heart failure and proteinuria, but this should not vary by incarceration history. We did not account for medications received outside the VHA system, though this effect would likely be small, as most VHA patients get their medications from the VHA system. ${ }^{15,}{ }^{41}$ In addition, our measurement of primary care engagement was limited and may not completely describe the interaction between primary care engagement and BP control.

For our exposure of interest, history of incarceration, we could not distinguish between exposure to jail versus prison. This is a potential limitation, as these two correctional environments may have different effects on control of BP. Our findings may not be generalizable to individuals receiving care outside the VHA system, where individuals with and without a history of incarceration may have differential levels of access to medical care, medications, and care coordination prior to release. $^{12}$ Finally, generalizability of our findings may be limited, as VACS is a cohort of HIV-infected and matched controls and does not represent the VHA patient population. Notwithstanding these limitations, these data come from clinical, pharmacologic, and administrative databases, and provide robust information on the health outcomes and potential confounders of individuals released from correctional facilities.

\section{CONCLUSIONS}

In patients with hypertension, a history of recent incarceration is associated with higher odds of having uncontrolled BP compared with participants who have not been recently incarcerated. We suggest that more longitudinal studies need to be conducted, looking at the relationship between incarceration and BP control. Our study also suggests that specific interventions need to be developed for patients with a recent history of incarceration, to improve BP control and to reduce disparities in cardiovascular outcomes.

Acknowledgments: This material is based upon work supported by the Department of Veterans Affairs, Veterans Health Administration, and the VA Office of Research and Development. The views expressed in this article are those of the authors and do not necessarily reflect the position or policy of the Department of Veterans Affairs. Funding for this study was provided by the National Institute on Drug Abuse (1R03DA031592); NIDA had no further role in study design; in the collection, analysis and interpretation of data; in the writing of the report; or in the decision to submit the paper for publication. VACS is funded by the National Institute on Alcohol Abuse and Alcoholism (U10 AA013566, U24 AA020794, and UO1 AA020790). Emily Wang received financial support through a career development award from the National Heart Lung Blood Institute (K23 HL103720) and Yale Center for Clinical Investigation Clinical and Translational Science Award (UL1 RRO24139).

Corresponding Author: Benjamin A. Howell, MD MPH; Department of Internal Medicine, Yale University School of Medicine, P.O. Box 208030, New Haven, CT 06520, USA (e-mail: benjamin.howell@yale.edu).

\section{Compliance with Ethical Standards:}

Conflict of Interest: Dr. Fiellin has received honoraria from Pinney Associates for serving on an external advisory board monitoring the diversion and abuse of buprenorphine products. The other authors declare that they do not have a conflict of interest.

\section{REFERENCES}

1. Pew Center on the States. One in 100: Behind Bars in America 2008. Washington: The Pew Charitable Trusts; 2008.

2. Carson EA. Prisoners in 2013. Washington (DC): Department of Justice, Bureau of Justice Statistics; 2014 Sep 30. Report No.: NCJ 247282.

3. Bonczar TP. Prevalence of imprisonment in the U.S. population, 19742001. Washington (DC): U.S. Department of Justice, Bureau of Justice Statistics; 2003 Aug. Report No.: NCJ 197976.

4. Binswanger IA, Krueger PM, Steiner JF. Prevalence of chronic medical conditions among jail and prison inmates in the USA compared with the general population. J Epidemiol Community Health. 2009;63(11):912-9.

5. Fazel S, Baillargeon $\mathbf{J}$. The health of prisoners. Lancet. 2011;377(9769):956-65.

6. Harzke AJ, Baillargeon JG, Pruitt SL, Pulvino JS, Paar DP, Kelley MF Prevalence of chronic medical conditions among inmates in the Texas prison system. J Urban Health. 2010;87(3):486-503.

7. Wang EA, Pletcher M, Lin F, Vittinghoff E, Kertesz SG, Kiefe CI, Bibbins-Domingo $\mathbf{K}$. Incarceration, incident hypertension, and access to health care: findings from the coronary artery risk development in young adults (CARDIA) study. Arch Intern Med. 2009;169(7):687-93.

8. Binswanger IA, Stern MF, Deyo RA, Heagerty PJ, Cheadle A, Elmore JG, Koepsell TD. Release from prison-a high risk of death for former inmates. N Engl J Med. 2007;356(2): 157165. 
9. Binswanger IA, Blatchford PJ, Mueller SR, Stern MF. Mortality after prison release: opioid overdose and other causes of death, risk factors, and time trends from 1999 to 2009. Ann Intern Med. 2013;159(9):592-600.

10. Wang EA, Wang Y, Krumholz HM. A high risk of hospitalization following release from correctional facilities in medicare beneficiaries: a retrospective matched cohort study, 2002 to 2010. JAMA Intern Med. 2013;173(17): 1621-8.

11. Wortzel HS, Blatchford P, Conner L, Adler HE, Binswanger IA. Risk of death for veterans on release from prison. J Am Acad Psychiatry Law. 2012;40(3):348-54.

12. Blue-Howells JH, Clark SC, van den Berk-Clark C, McGuire JF. The US Department of Veterans Affairs Veterans Justice Programs and the sequential intercept model: case examples in national dissemination of intervention for justice-involved veterans. Psychol Serv. 2013;10(1):48-53.

13. Olubodun $\mathbf{J}$. Prison life and the blood pressure of the inmates of a developing community prison. J Hum Hypertens. 1996;10(4):235-8.

14. James PA, Oparil S, Carter BL, et al. 2014 evidence-based guideline for the management of high blood pressure in adults: report from the panel members appointed to the Eighth Joint National Committee (JNC 8). JAMA. 2014;311(5):507-20.

15. Justice AC, Dombrowski E, Conigliaro J, et al. Veterans aging cohort study (VACS): overview and description. Med Care. 2006;44(8 Suppl 2):S13-24.

16. Figueiredo DA, Azevedo A, Pereira MA, de Barros HE. Definition of hypertension: the impact of number of visits for blood pressure measurement. Rev Port Cardiol. 2008;28(7-8):775-83.

17. Fletcher RD, Amdur RL, Kolodner R, McManus C, Jones R, Faselis C, Kokkinos P, Singh S, Papademetriou V. Blood pressure control among US veterans: a large multiyear analysis of blood pressure data from the Veterans Administration health data repository. Circulation. 2012;125(20):2462-8

18. Bush K, Kivlahan DR, McDonell MB, Fihn SD, Bradley KA. The AUDIT alcohol consumption questions (AUDIT-C): An effective brief screening test for problem drinking. Ambulatory Care Quality Improvement Project (ACQUIP). Alcohol Use Disorders Identification Test. Arch Intern Med. 1998;158(16): 1789-95.

19. McGinnis KA, Justice AC, Kraemer KL, Saitz R, Bryant KJ, Fiellin DA Comparing alcohol screening measures among HIV-infected and -uninfected men. Alcohol Clin Exp Res. 2013;37(3):435-42.

20. Justice AC, Lasky E, McGinnis KA, Skanderson M, Conigliaro J, Fultz SL, Crothers K, Rabeneck L, Rodriguez-Barradas M, Weissman SB, Bryant K. Medical disease and alcohol use among veterans with human immunodeficiency infection: a comparison of disease measurement strategies. Med Care. 2006;44(8):S52-60.

21. Spitzer RL, Kroenke K, Williams JB, Patient Health Questionnaire Primary Care Study Group. Validation and utility of a self-report version of PRIME-MD: the PHQ primary care study. JAMA. 1999;282(18):1737-44.

22. Horberg MA, Aberg JA, Cheever LW, Renner P, Kaleba EO, Asch SM. Development of national and multiagency HIV care quality measures. Clin Infect Dis. 2010;51(6):732-8.

23. Steiner JF, Prochazka AV. The assessment of refill compliance using pharmacy records: methods, validity, and applications. J Clin Epidemiol. 1997;50(1):105-16.

24. Baron RM, Kenny DA. The moderator-mediator variable distinction in social psychological research: conceptual, strategic, and statistical considerations. J Pers Soc Psychol. 1986;51(6):1173.
25. Fox AD, Anderson MR, Bartlett G, Valverde J, Starrels JL, Cunningham Co. Health outcomes and retention in care following release from prison for patients of an urban post-incarceration transitions clinic. $\mathrm{J}$ Health Care Poor Underserved. 2014;25(3):1139-52.

26. Lincoln T, Kennedy S, Tuthill R, Roberts C, Conklin TJ, Hammett TM. Facilitators and barriers to continuing healthcare after jail: a communityintegrated program. J Ambul Care Manage. 2006;29(1):2-16.

27. Carroll D, Davey Smith G, Sheffield D, Shipley MJ, Marmot MG. The relationship between socioeconomic status, hostility, and blood pressure reactions to mental stress in men: data from the Whitehall II study. Health Psychol. 1997;16(2):131-6.

28. Iribarren C, Sidney S, Bild DE, Liu K, Markovitz JH, Roseman JM, Matthews K. Association of hostility with coronary artery calcification in young adults: The CARDIA study. Coronary artery risk development in young adults. JAMA. 2000;283(19):2546-51.

29. Yan LL, Liu K, Matthews KA, Daviglus ML, Ferguson TF, Kiefe CI. Psychosocial factors and risk of hypertension: the coronary artery risk development in young adults (CARDIA) study. JAMA. 2003;290(16):213848.

30. Schnittker J, John A. Enduring stigma: the long-term effects of incarceration on health. J Health Soc Behav. 2007;48(2):115-30.

31. Kelly PJ, Ramaswamy M, Hsiang-Feng C, Denny D. Wellness and illness self-management skills in community corrections. Issues Ment Health Nurs. 2015;36(2):89-95.

32. Hunter Buskey RN, Mathieson K, Leafman JS, Feinglos MN. The effect of blood glucose self-monitoring among inmates with diabetes. J Correct Health Care. 2015;21(4):343-54.

33. Meyer JP, Cepeda J, Wu J, Trestman RL, Springer SA. Optimization of human immunodeficiency virus treatment during incarceration: viral suppression at the prison gate. JAMA Intern Med. 2014;174(5):721-9.

34. U.S. Department of Veterans Affairs. Health Care for Re-entry Veterans (HCRV) Program. Available at http://www.va.gov/homeless/reentry.asp. Accessed June 22, 2016.

35. Flanagan NA. Transitional health care for offenders being released from United States prisons. Can J Nurs Res. 2004;36(2):38-58.

36. Wang EA, Hong CS, Samuels L, Shavit S, Sanders R, Kushel M. Transitions clinic: creating a community-based model of health care for recently released California prisoners. Public Health Rep. 2010;125(2): 171-7.

37. Wang EA, McGinnis KA, Long JB, et al. Incarceration and health outcomes in HIV-infected patients: the impact of substance use, primary care engagement, and antiretroviral adherence. Am J Addict. 2015;24(2):178-84.

38. Redmond N, Hicks LS, Cheng DM, et al. Association of recent incarceration with traumatic injury, substance use related health consequences, and health care utilization. J Addict Med. 2014;8(1):66-72.

39. Howell BA, Guydish J, Kral AH, Comfort M. Prevalence and factors associated with smoking tobacco among men recently released from prison in California: a cross-sectional study. Addict Behav. 2015;50:157-60.

40. Franklin SS, Larson MG, Khan SA, Wong ND, Leip EP, Kannel WB, Levy D. Does the relation of blood pressure to coronary heart disease risk change with aging? The Framingham Heart Study. Circulation. 2001;103(9): 1245-9.

41. Smith MW, Joseph GJ. Pharmacy data in the VA health care system. Med Care Res Rev. 2003;60(3 Suppl):92S-123. 